\title{
ASIGNACION DE DERECHOS DE USUFRUCTO EN MERCADOS INFORMALES: EVIDENCIA DESDE LAS CALLES
}

\section{ALLOCATION OF USUFRUCT RIGHTS IN INFORMAL MARKETS: EVIDENCE FROM THE STREETS}

\section{JOSE MARIA CABRERA*}

Centro de Investigación en Economía Aplicada, Universidad de Montevideo

\section{ALEJANDRO CID**}

Centro de Investigación en Economía Aplicada, Universidad de Montevideo

\begin{abstract}
We analyze the results of a policy of massive allocation of usufruct rights to cuidacoches: persons performing surveillance of parked vehicles in the streets. Surprisingly, despite the low cost and the considerable benefits to legally acquiring the right of use on the block, half of the potential beneficiaries have rejected the subscription to the program. In order to understand this market and the mobility between being in the legal framework or outside the law, we built a unique database containing economic and sociodemographic information from cuidacoches in Montevideo. We highlight four findings: the heterogeneity in the reasons for accepting or rejecting the legal framework; the protection of the right of usufruct on the block as the main perceived benefit of complying with the legal framework; the desire to change jobs for the vast majority, and the low saving capacity.
\end{abstract}

Keywords: Usufruct rights, property rights, social mobility, aspirations, labor market.

JEL Classification: $\mathrm{I3}, \mathrm{J} 4, \mathrm{O} 12$.

* E-mail: jmcabrera@um.edu.uy, http://fcee.um.edu.uy/ Prudencio de Pena 2544, Montevideo 11600, Uruguay. Teléfono: +5982707 4461.

** E-mail: acid@um.edu.uy, http://fcee.um.edu.uy/ Prudencio de Pena 2544, Montevideo 11600, Uruguay. Teléfono: +5982707 4461 . 


\section{Resumen}

Analizamos los resultados de una política de asignación masiva de derechos de usufructo a los cuidacoches, personas que desempeñan tareas de vigilancia de vehículos aparcados en las calles. Sorprendentemente, a pesar del costo reducido y los considerables beneficios de adquirir legalmente el derecho de usufructo sobre la cuadra, la mitad de los potenciales beneficiarios han rechazado la suscripción a ese programa. Con el fin de entender este mercado y la movilidad entre estar en el marco legal o fuera de la ley, construimos una base de datos inédita que contiene información económica y sociodemográfica de los cuidacoches en Montevideo. En los resultados encontrados se destacan cuatro observaciones: la heterogeneidad en las razones de aceptación o rechazo del marco legal diseñado para los cuidacoches; la protección del derecho de usufructo sobre la cuadra como el beneficio principal percibido de adecuarse al marco legal; la aspiración a cambiar de trabajo de la inmensa mayoría, y la capacidad de ahorro reducida.

Palabras clave: Derechos de usufructo, derechos de propiedad, movilidad social, aspiraciones, mercado laboral.

Clasificación JEL: I3, J4, O12.

\section{INTRODUCCION}

El mercado informal de los cuidadores de vehículos plantea preguntas de sumo interés para la ciencia económica. Por un lado, la evidencia empírica muestra una importante participación del sector informal en los países en vías de desarrollo. Y esa informalidad está asociada a mayores niveles de pobreza y vulnerabilidad social (nulo o peor acceso a cobertura de salud, a seguros por enfermedad o a derechos de jubilación, escasa inversión en capital físico y humano). Por tanto el primer cuestionamiento que nos plantea la existencia de un mercado informal de cuidacoches es: ¿qué características tienen las personas que están sumergidas en ese peculiar mercado informal y qué medidas de política se pueden sugerir para que abandonen esa situación de vulnerabilidad social?

La teoría económica sugiere una alta correlación entre la existencia de derechos de propiedad y el grado de protección de esos derechos, con los resultados económicos. Esto hace especialmente interesante el estudio del mercado informal de los cuidacoches, donde personas detentan el derecho de usufructo de un activo -una cuadra- ejerciendo un permiso legal otorgado por la autoridad competente o defendiendo una situación de hecho. Así surge una segunda pregunta relevante para la ciencia económica: ¿cómo se distribuyen los derechos de usufructo en un mercado informal de cuidadores de vehículos, cuáles son los mecanismos que están detrás de las asignaciones de derechos y cuáles son los vínculos entre esos derechos y los resultados económicos observados? 
El análisis del trabajo informal vinculado a un derecho de usufructo tiene una importancia medular para entender fenómenos contemporáneos como los que se observan en cuadras donde se cuidan o lavan vehículos sin ningún tipo de regulación, calles donde se levanta basura a cambio de una contribución económica voluntaria o en ferias donde se venden bienes en zonas asignadas informalmente. En el caso particular de los automóviles, en los países de América Latina existe la figura del cuidador de vehículos: personas que trabajan en la calle por cuenta propia, cuidando los vehículos estacionados (aunque el servicio no sea solicitado por los conductores) a cambio de una propina. En algunos casos se ha tratado de prohibir, regular o legislar acerca de este fenómeno. En cada país se les conoce por distintos nombres: desde los "vieneviene o franeleros" en México, pasando por los "cuida autos o guardias" en Chile, los "franelinhas" en Brasil, los "celadores, vigilantes o guachimanes" en Colombia, "cuida carros" en Perú, los "trapitos" en Argentina, hasta los "cuidacoches" en Uruguay, por nombrar algunos. Con el fin de explorar estos mercados presentes en varios países de Latinoamérica, construimos y analizamos una base de datos inédita respecto de una proporción significativa de los cuidadores de vehículos en Montevideo. La capital de Uruguay es especialmente atractiva para estudiar la dinámica de estos mercados informales de derechos de usufructo, porque esta urbe capitalina ha experimentado una explosión de personas entrando al mercado de cuidacoches en las últimas dos décadas. Otro factor que hace muy interesante a Montevideo es la existencia de una política activa del gobierno departamental -Intendencia Municipal de Montevideo (IMM) - para regular esos derechos de usufructo entregando permisos legales. En efecto, cualquier cuidador puede solicitar ante las autoridades departamentales la posesión de una cuadra para trabajar, y de esta forma convertirse en propietario exclusivo del derecho de trabajar allí en el cuidado de vehículos.

Mejorar nuestra comprensión de los mercados laborales informales, y la evolución de la institucionalidad y derechos de propiedad en esos mercados, es crucial para realizar sugerencias a los diseñadores de políticas públicas y motivar futuras investigaciones en este campo que afecta a tantas personas.

El trabajo está estructurado de la siguiente forma. En la Sección 2 realizaremos una revisión de la literatura, con un especial foco en los derechos de propiedad y en la informalidad. En la Sección 3 hacemos una descripción de la oferta de permisos de propiedad en el mercado de los cuidacoches. Describimos la base de datos que construimos en la Sección 4. El análisis lo desarrollamos en distintos apartados de la Sección 5.

\section{REVISION DE LA LITERATURA}

Tradicionalmente la literatura atinente al desarrollo y crecimiento ha puesto énfasis en el ahorro y en la acumulación de capital, dentro de un mundo con derechos de propiedad perfectamente definidos y protegidos. Sin embargo el desarrollo de la escuela institucional ha puesto en el centro de la discusión a los derechos de propiedad que efectivamente tienen las personas en un mundo que no está libre de la fricción (Demsetz, 1967). Gërxhani (2004) provee un resumen de las contribuciones 
de la literatura en el sector informal y compara estos hallazgos de la literatura previa entre dos tipos de países con marcadas diferencias en las instituciones: los países desarrollados y los que están en vías de desarrollo. Así, Albrecht, Navarro y Vroman (2009) observan la sustancial participación del sector informal en los mercados laborales de los países en desarrollo -más del 50\% de los trabajadores están empleados en el sector informal en América Latina- y encuentran que las políticas diseñadas para el mercado formal afectan significativamente el tamaño y la composición del empleo en el sector informal.

Los derechos de propiedad afectan la asignación de recursos moldeando los incentivos que mueven a los individuos a lanzarse a desarrollar actividades productivas involucrando el activo que poseen, tomando decisiones de inversiones que puedan mantener o mejorar el valor de ese activo, o incluso vender ese activo (Besley, 1995). En este sentido, Field (2007) examina los efectos de un programa de asignación de derechos de propiedad a un importante número de personas en Perú. Sus estimaciones sugieren que el obtener el derecho de propiedad aumenta la cantidad de horas trabajadas, y sustituye horas de trabajo en el hogar por horas de trabajo afuera de la casa. Lanjouw y Levy (2002) estudian los efectos de un proceso de asignación de derechos de propiedad en Ecuador y se centran en estudiar el impacto de esa política en el valor del activo objeto de la propiedad. Galiani y Schargrodsky (2010) estudian los efectos de asignaciones de derecho de propiedad de tierras en Argentina. Los resultados sugieren que el poseer derechos de propiedad parece ser una importante herramienta para reducir la pobreza y que el mecanismo detrás de estos resultados es el incremento en la inversión en capital humano y físico. Gandelman (2009) aprovecha un experimento natural de asignación de títulos de propiedad en Uruguay para ver el efecto ingreso de esa asignación (dirigir recursos hacia el consumo de bienes y servicios -educación, por ejemplo-) y el efecto sustitución (dirigir recursos hacia la inversión en el activo físico), concluyendo que el impacto final de la política de asignación de derechos de propiedad parece atentar contra la inversión en capital humano de los hijos (la asignación a mayor inversión en el activo físico termina relegando a la asignación a capital humano).

Besley, Burchardi y Ghatak (2010) proveen un considerable resumen de la literatura empírica y teórica para entender la relación entre los derechos de propiedad y el desarrollo económico. Los autores comienzan definiendo lo que se entiende por derecho de propiedad, esto es, el derecho de una persona de usar un bien o un activo para consumo o para generar ingresos (derechos de usufructo). También comprende la del derecho a transferir ese bien o activo a otra persona por medio de la venta, el regalo, etc. (derechos de transferencia). Ahora bien, esos derechos de propiedad no son un fenómeno exógeno sino que evolucionan en el tiempo movidos por fuerzas de distinto calibre como las políticas, sociales, económicas, etc. Besley, Burchardi y Ghatak (2010) se hacen dos grandes preguntas para motivar el resumen de la literatura. La primera es: ¿cuáles son los mecanismos por los que el derecho de propiedad afecta la actividad económica? Los autores señalan cuatro aspectos en los que los derechos de propiedad afectan a la actividad económica. El primero es el riesgo de expropiación: la inseguridad en los derechos de propiedad hace que se vuelva incierto hacerse con los frutos de su inversión y esfuerzos. El segundo es que 
los derechos de propiedad inseguros implican que las personas tienen que incurrir en costos para defender su propiedad y esto es improductivo. El tercero es que los derechos de propiedad mal definidos atentan contra las ganancias del comercio que requiere que los activos sean usados por aquellos en los que esos activos son más productivos (y los derechos de propiedad mal definidos atentan contra la movilidad de los activos hacia los sectores donde sean más productivos). El cuarto es el uso del derecho de propiedad para apoyar otras transacciones (por ejemplo, para acceder a algún tipo de oferente financiero).

La segunda pregunta que se hacen los autores es: ¿cuáles son los determinantes de los derechos de propiedad? Contribuyen a contestar esta pregunta estudiando cómo los sistemas de derecho de propiedad son creados y cómo evolucionan en el tiempo, y observando a los ganadores y perdedores en la distribución histórica de esos derechos de propiedad y a las instituciones que dan forma al proceso por el que algunos derechos de propiedad son creados y otros son destruidos. Para responder esta segunda gran pregunta los autores se dedican a estudiar la historia y las experiencias contemporáneas. Un mensaje central que extraen los autores es que, a la hora de entender los derechos de propiedad y su evolución, los investigadores han de evitar pensar la extensión de los derechos de propiedad de una manera monolítica, pues tanto la creación de esos derechos como su impacto son heterogéneos, como los señala la evidencia empírica y las predicciones de los marcos teóricos.

Finalmente, la literatura respecto de mercados informales también incluye estudios enfocados en la posible desutilidad de participar en la economía informal y analiza los efectos de monitorear y castigar la informalidad (Fugazza y Jacques, 2003).

\section{DESCRIPCION DEL MERCADO DE DERECHOS DE USUFRUCTO SOBRE LAS CUADRAS}

La Unidad de Registro de Cuidadores de Vehículos de la Intendencia Municipal de Montevideo (IMM) es quien administra los permisos (o carné) de cuidacoches para cada cuadra. Esta administración de permisos por parte de la IMM se hace en forma centralizada, es decir, no son los municipios -particiones zonales de la IMMlos que tienen la potestad de asignar permisos, revocarlos o resolver problemas, sino que toda esta área es de manejo exclusivo de la IMM. La IMM puede asignar a una misma cuadra más de un permiso si divide los horarios. El principal beneficio que reporta el permiso al cuidacoches es que se le asigna una cuadra donde podrán cuidar vehículos sin que ningún otro potencial cuidador pueda obtener un permiso para trabajar en esa misma cuadra. En definitiva, quien posee el permiso obtiene el derecho a usufructuar esa cuadra cuidando vehículos. Otro beneficio es que, al otorgársele un permiso, el cuidador obtiene un chaleco y un carné impreso: ambas cosas le ayudan a identificarse exteriormente y recibir la protección de la IMM en el usufructo de esa cuadra frente a potenciales cuidacoches que lo quieran desplazar por la fuerza. Un beneficio adicional es que puede realizar aportes para su futura jubilación y obtener así, al mismo tiempo, cobertura ante accidentes laborales y acceso a cobertura de salud para sí mismo y para sus hijos. 
Los requisitos para obtener el permiso son: (1) tener cédula de identidad vigente - el costo es 173 pesos uruguayos ( 8 dólares), pero se puede obtener gratis demostrando indigencia- y llevar una fotocopia; (2) poseer carné de salud -el costo es 260 pesos, pero se puede obtener gratis demostrando indigencia-y llevar una fotocopia; (3) obtener el certificado de antecedentes judiciales (lo que popularmente se conoce como certificado de buena conducta) cuyo costo es 65 pesos $^{1}$; (4) 3 copias de fotografía que permita identificarlo en el carné que le otorga la IMM al cuidador (costo aproximado 30 pesos). En suma, el costo global que enfrenta el cuidacoches para obtener el permiso va desde 95 pesos hasta los 528 pesos.

De cumplir estos requisitos, se le otorga al cuidador de vehículos un permiso provisorio por 15 días. Si en esos 15 días no se observan reclamos ni denuncias, se le otorga el permiso final. El permiso es en principio permanente pero puede ser revocable en algunas circunstancias (por ejemplo, en el caso de faltas graves). Existen cerca de 1.700 cuidacoches activos en la IMM (tienen permiso, van a los controles mensuales, están en su cuadra, etc.).

$\mathrm{Al}$ obtener el permiso, el cuidacoches también adquiere responsabilidades. $\mathrm{La}$ primera de ellas es que, en caso de una eventual denuncia de un conductor que estaciona en la cuadra asignada al cuidacoches, la IMM se dirige al cuidacoches correspondiente. Una segunda obligación que se adquiere con el permiso es que el cuidador de vehículos ha de pagar un mono tributo mensual al BPS. El aporte del tributo será de 807 pesos (sin cobertura médica), de 2.107 pesos con cobertura médica para los que no tienen hijos, o de 2.343 pesos con cobertura médica para los que tienen hijos -así, estos hijos obtienen cobertura de esta manera-.

Otra obligación que contrae el cuidacoches es acercarse a la IMM cada mes para firmar. La IMM señala que la razón de este procedimiento es buscar un vínculo más cercano con el cuidador. Si no firma no se le da de baja, pero se estudia caso a caso para ver la causa (por ejemplo, por razones de enfermedad).

\section{Estructura del mercado}

El mercado está organizado de forma descentralizada. Los cuidacoches no están agrupados u organizados para solicitar y repartir los derechos de propiedad sobre las calles. Se presentan individualmente en la IMM y si la calle que están solicitando se encuentra disponible, entonces se hacen propietarios del usufructo sobre la misma. Los permisos son individuales y no transferibles. El 96\% de los cuidacoches con permiso encuestados declaran que el permiso que poseen es de ellos; el $4 \%$ restante afirma que el permiso que están usando no es de ellos, pero únicamente 4 personas declaran que lo compraron (el resto indica que el permiso pertenece a algún pariente, por ejemplo). Por tanto, no existe un comercio secundario instaurado de estos permisos. El $31 \%$ declara que existen personas de referencia a las que hay que solicitarle su beneplácito antes de poder trabajar (cuidacoches que ya están en la zona, por ejemplo). Los cuidacoches que no poseen el permiso de la intendencia es más probable que

1 El certificado de antecedentes judiciales no implica que para obtener un permiso sea imprescindible no cargar con antecedentes. La IMM se reserva el derecho de estudiar cada caso. 
tengan que solicitar el beneplácito de algún referente de la zona para poder trabajar (36\%) en comparación con los que declaran tener permiso (26\%). La diferencia es significativa al $5 \%(p=0,020)$. De todas formas estos referentes no reciben beneficios monetarios de los cuidacoches (no es similar a una mafia). Únicamente 5 cuidacoches de la muestra tienen que entregar parte de sus ingresos a otra persona (que no sea familiar o compañero de trabajo) $)^{2}$.

\section{BASE DE DATOS}

En mayo de 2013 hicimos un primer relevamiento de la distribución geográfica de los cuidacoches recorriendo las distintas zonas de Montevideo. El objetivo era dividir Montevideo en zonas similares en número potencial de cuidacoches para luego asignar encuestadores a cada zona. Antes de lanzar la encuesta, se realizaron varias entrevistas piloto a cuidacoches para afinar el contenido y la forma del cuestionario. Estas entrevistas pilotos se realizaron en una pequeña zona que luego se excluyó para evitar sesgos por haber ya sido entrevistados. Por las características del cuidador de vehículos que se encontraron en esas entrevistas iniciales, se decidió que el cuestionario no sea autoadministrado sino que sea el encuestador el que pregunte y rellene el cuestionario. La encuesta se realizó en el período junio-julio de 2013 y se llegó a encuestar a 520 cuidacoches. La tasa de rechazos fue casi nula. Para facilitar la disposición del cuidacoches para responder la encuesta, se hizo énfasis en el propósito de que la encuesta sirviera para difundir datos agregados de los cuidadores de vehículos que, respetando la intimidad de cada uno, pudiera dar a conocer la realidad de su situación y así obtener apoyos para superar las situaciones de vulnerabilidad social en que muchas veces se encuentran. También con el fin de predisponer en mejor medida al cuidacoches para contestar la encuesta, se le entregó a cada uno un incentivo que consistía en un número que asignaba un premio equivalente a 300 pesos de coincidir con los números ganadores de la lotería pública. Se pautó que en caso de encontrar más de un cuidador de vehículos en una cuadra al momento de la entrevista, esta se realizara solamente a quien esos cuidadores identificaban como el propietario de la cuadra. Las entrevistas se centraron exclusivamente en cuidadores de vehículos que trabajaban en las distintas cuadras de lunes a viernes entre las 10 y las 18 horas (de esta manera, con el fin de conseguir mayor homogeneidad en la muestra, se dejó afuera a cuidadores de vehículos que aparecen en ocasiones de espectáculos públicos, fiestas, etc. - estos serán objeto de una futura investigación-). Cada encuestador, además de entrevistar al cuidacoches, tuvo asignada la tarea de rellenar un mapa de su zona con la localización exacta del cuidacoches (cuadra donde trabaja, delimitada por dos calles). En el Anexo 2 mostramos la ubicación de los cuidacoches. La mayoría de los encuestados se encuentran en la zona sur de Montevideo. Esto se debe a que esa zona tiene cuatro características importantes para el tipo de trabajo analizado: es una

2 Hay referencias anecdóticas de un par de cuadras en las que el dueño del permiso arrienda la cuadra a otros cuidacoches, que le entregan una parte de la recaudación al final del día. Pero son casos aislados y no detectamos un mercado de reventa o alquiler de estos permisos. 
zona de altos ingresos, densamente poblada, con insuficientes lugares para aparcar y con una gran rotación diaria de vehículos que estacionan (zona de bancos, oficinas, universidades, escuelas, etc.).

Además de datos socioeconómicos, se extrajo información del "tipo" de cuidacoches, pues, al finalizar la entrevista, el encuestador tenía que rellenar parte de la encuesta donde se pregunta por situaciones objetivas externas que encontró durante la entrevista.

La motivación para obtener datos que permitiera identificar el "tipo" de cuidacoches surgió de las encuestas piloto donde se constató una gran heterogeneidad en el aspecto exterior del cuidacoches que daba indicación de su compromiso con el trabajo bien hecho, de su porte externo y de sus cualidades para el trato con los clientes. Así, para obtener el "tipo" de cuidacoches, el cuestionario hacía cuatro preguntas: (1) si el cuidacoches se encontraba alcoholizado o bajo los efectos de drogas al momento de la entrevista; (2) si su aspecto era desalineado; (3) el estado de su dentadura; (4) la calidad de su lenguaje.

El posible rol del "tipo" de cuidacoches en los resultados económicos que obtienen se inserta en la literatura de Mismatch Hypotesis, que argumenta que las personas con muy bajo nivel de habilidades y capital humano experimentan resultados magros en el mercado laboral, porque están desconectadas de las exigencias de los demandantes de trabajo (Acemoglu y Autor, 2011).

\section{ANALISIS}

\section{Características de los cuidacoches}

Como se observa en la Tabla 1, exactamente la mitad de los trabajadores encuestados declaran contar con permiso de la IMM, por lo que tienen derechos de usufructo sobre la cuadra. La otra mitad de los cuidacoches realizan su trabajo sin contar con permiso de la IMM. Las mujeres son únicamente el $11 \%$ de los cuidacoches encuestados. La edad promedio es de 46,8 años, mientras que el cuidacoches más joven encuestado tenía 18 años de edad, y el mayor 85 . En cuanto al nivel educativo, el 60\% declara tener educación Primaria como el máximo nivel alcanzado -en Uruguay la educación Primaria comprende los primeros 6 años de educación formal luego del preescolar. La educación acumulada reducida en la mayor parte de los cuidadores de vehículos se alinea con lo que predice el modelo De Paula y Scheinkman (2011) acerca de la calidad de los emprendedores informales: su capital humano como emprendedores es reducido. También se constata empíricamente por Banerjee y Duflo (2006): los pobres invierten extremadamente poco en educación.

\section{Por qué trabajan de cuidacoches}

La razón principal para trabajar de los cuidacoches es que se encontraban desempleados. El 58\% declara que trabaja de cuidacoches porque no tenía otro trabajo; 
la siguiente razón en importancia es la categoría "otras" -que incluye problemas de salud-y la tercera es querer trabajar libremente, sin jefe ${ }^{3}$.

TABLA 1

\begin{tabular}{|l|r|r|r|r|c|}
\hline \multicolumn{1}{|c|}{ Variable } & Media & $\begin{array}{c}\text { Desvío } \\
\text { estándar }\end{array}$ & Mín. & Máx. & Observaciones \\
\hline Permiso & 0,497 & 0,500 & 0 & 1 & 507 \\
Mujer & 0,110 & 0,313 & 0 & 1 & 519 \\
Edad & 6,768 & 14,313 & 18 & 85 & 496 \\
Educ. máx: Primaria & 0,604 & 0,490 & 0 & 1 & 507 \\
\hline
\end{tabular}

Fields (2004) sistematiza tres caracterizaciones de los mercados de trabajo del sector informal y plantea hipótesis que pueden ayudar a explicar la entrada al mercado informal. La primera caracterización sería el considerar a la economía informal como un sector de libre entrada en el que quienes buscan trabajar entran solamente como último recurso. La segunda óptica sería considerar la economía informal como un sector deseable que los trabajadores prefieren respecto del sector formal. Finalmente, señala el autor, la economía informal puede verse con un dualismo interno, combinando las dos primeras caracterizaciones. Este dualismo interno parece reflejarse en las razones que esgrimen los cuidacoches al preguntárseles por qué optaron por ese trabajo. Entre las respuestas con mayor peso están el encontrarse desempleado -aquí se visualizaría este sector informal como un mercado de libre entrada por el que se opta como último recurso-, y la voluntad de querer trabajar con libertad de horarios, etc. -así el sector informal se convierte en un sector realmente deseable frente a los mayores requisitos para trabajar en el sector formal-.

\section{Beneficios de adecuarse al marco legal para cuidacoches}

En la Sección 3 planteamos los beneficios que obtienen según la reglamentación los cuidacoches cuando obtienen el permiso. Veremos ahora el punto de vista de los trabajadores. Tener el carné de cuidacoches reporta beneficios a los que lo poseen. Únicamente $0,4 \%$ de los que obtuvieron el permiso declara que no le otorga ningún beneficio. El principal beneficio que encuentran los cuidacoches es justamente que obtienen un derecho de usufructo sobre la cuadra: el $70 \%$ declara que "la cuadra es mía y nadie me puede sacar" (Tabla 2). En orden de importancia, los otros beneficios son: que la policía los defiende si lo quieren sacar (19\%), que les sirve el chaleco que da la IMM (14\%) y que pueden obtener mejores propinas $(14 \%)^{4}$. En los "otros" beneficios, declaran que con el permiso ganan el "respeto" de la gente.

3 Los valores numéricos que no están en las tablas, se encuentran en el Anexo 1.

4 Los porcentajes son no excluyentes, ya que podían señalar más de un motivo. Cuando se les pregunta que señalen el principal, el 67,5\% indica la propiedad de la cuadra. 


\section{TABLA 2}

\begin{tabular}{|l|c|c|c|c|c|}
\hline $\begin{array}{c}\text { Beneficios del permiso de la IMM } \\
\text { (solo para los que tienen permiso) }\end{array}$ & Media & $\begin{array}{c}\text { Desvío } \\
\text { estándar }\end{array}$ & Mín. & Máx. & Observaciones \\
\hline La cuadra es mía & 0,703 & 0,458 & 0 & 1 & 239 \\
Defensa de la cuadra por la policía & 0,190 & 0,393 & 0 & 1 & 237 \\
Chaleco que me dan & 0,137 & 0,344 & 0 & 1 & 234 \\
Mejores propinas & 0,135 & 0,342 & 0 & 1 & 237 \\
Aporto BPS & 0,042 & 0,202 & 0 & 1 & 236 \\
\hline
\end{tabular}

\section{Motivos por los que no obtienen el derecho de usufructo - Restricciones}

Empleando la Tabla 3, analizaremos ahora los motivos por los que los trabajadores de este mercado no obtienen el permiso de la IMM. Debido a que conseguir el derecho de usufructo sobre una cuadra tiene beneficios, y los costos parecen bajos, nos preguntamos cuáles son las restricciones por las que no se accede a la obtención del carné de la IMM. Los principales motivos son que no necesitan el permiso para trabajar en el lugar (25\% de las respuestas) y que no ganan nada con tener permiso o no tienen ganas de sacarlo (32\%). Las barreras monetarias también existen: el $19 \%$ declara no tener dinero para los trámites y $22 \%$ que pierde horas de trabajo en hacer los trámites. La falta de información es otra restricción a la que se enfrentan los cuidacoches: $19 \%$ declara que no tienen suficiente información de los pasos a dar para obtener el carné de la IMM. Entendemos que existe margen para aumentar la cantidad de cuidacoches que se pasan al marco legal (i.e., que los cuidacoches obtengan el permiso que otorga la IMM para explotar el usufructo de cada cuadra) en este mercado, con campañas de información y eventualmente incentivos monetarios.

TABLA 3

\begin{tabular}{|l|c|c|c|c|c|}
\hline $\begin{array}{c}\text { Motivos por los que no obtuvo permiso } \\
\text { de la IMM (solo para los que no tienen) }\end{array}$ & Media & $\begin{array}{c}\text { Desvío } \\
\text { estándar }\end{array}$ & Mín. & Máx. & Observaciones \\
\hline No necesito el permiso & 0,253 & 0,436 & 0 & 1 & 257 \\
Pierdo horas de trabajo & 0,212 & 0,409 & 0 & 1 & 255 \\
No tenía información & 0,193 & 0,395 & 0 & 1 & 254 \\
No tengo ganas & 0,191 & 0,394 & 0 & 1 & 256 \\
No tiene dinero para trámites & 0,188 & 0,392 & 0 & 1 & 255 \\
Es complicado sacar el permiso & 0,133 & 0,341 & 0 & 1 & 255 \\
No gano nada con el permiso & 0,130 & 0,337 & 0 & 1 & 254 \\
Queda lejos para ir la IMM & 0,114 & 0,319 & 0 & 1 & 254 \\
No obtuvo certificado de buena conducta & 0,094 & 0,293 & 0 & 1 & 255 \\
Difícil tramitar el carné de salud & 0,079 & 0,270 & 0 & 1 & 254 \\
No tengo cédula o documentos & 0,059 & 0,236 & 0 & 1 & 255 \\
Malos resultados de carné de salud & 0,039 & 0,195 & 0 & 1 & 254 \\
No pude sacar las foto carné & 0,020 & 0,139 & 0 & 1 & 254 \\
\hline
\end{tabular}




\section{¿Quiénes obtienen legalmente el derecho de usufructo sobre la cuadra?}

Para las mujeres, es $17 \%$ más probable que obtengan el permiso de la IMM $(\mathrm{p}=0,012)$. Una hipótesis posible es que las mujeres recurren a obtener el permiso de la IMM para evitar tener que utilizar la fuerza en la defensa del derecho de propiedad (si tienen el permiso, pueden recurrir a la IMM para que la autoridad departamental las defienda ante posibles intrusos). Otra posible explicación es que las mujeres, de por sí, en cualquier mercado laboral, trabajan en mayor medida de manera formal en comparación a los hombres (Bucheli y Ceni, 2007), y esta mayor tendencia a la formalidad laboral se puede ver representada en una mayor probabilidad de obtener el permiso de la IMM. Las personas de mayor edad tienen una mayor probabilidad de tener el carné de la IMM $(\mathrm{p}<0,01)$. Es más probable que estuvieran trabajando de cuidacoches cuando comenzó la política de asignación masiva de derechos de usufructo sobre las cuadras y hayan obtenido su permiso antes que otros, o hayan tenido más tiempo para hacer los trámites. Los cuidacoches con permiso llevan más años en este trabajo que los que no tienen permiso (11,67 años vs. 7,28, con un valor-p de la diferencia de medias $<0,001)$.

\section{Por qué trabaja de cuidacoches}

Como se observa en la Tabla 4, los motivos por los que las personas han comenzado a trabajar como cuidacoches no difieren mayormente entre los trabajadores con permiso y sin permiso. Cada columna de la Tabla 4 es una regresión lineal de cada uno de los motivos para ser cuidacoches respecto de las variables "Permiso" (variable binaria

\section{TABLA 4}

MOTIVOS POR LOS CUALES TRABAJAN DE CUIDACOCHES

(Cuidacoches con Permiso vs. sin Permiso)

\begin{tabular}{|l|c|c|c|c|c|}
\cline { 2 - 6 } \multicolumn{1}{c|}{} & $(1)$ & $(2)$ & $(3)$ & $(4)$ & $(5)$ \\
\cline { 2 - 6 } \multicolumn{1}{c|}{} & Trabajar & Ganaba & Desempleado & Preso & $\begin{array}{c}\text { Otra } \\
\text { razón }\end{array}$ \\
\hline \multirow{2}{*}{ Permiso } & 0,039 & $-0,008$ & $-0,072$ & $-0,044 * * *$ & 0,017 \\
& {$[0,037]$} & {$[0,034]$} & {$[0,048]$} & {$[0,016]$} & {$[0,041]$} \\
Mujer & $-0,015$ & $-0,001$ & 0,105 & $-0,028^{* * *}$ & $-0,087$ \\
& {$[0,054]$} & {$[0,047]$} & {$[0,073]$} & {$[0,008]$} & {$[0,061]$} \\
Edad & $-0,002$ & $-0,003 * *$ & $-0,000$ & $-0,001$ & $0,005^{* * *}$ \\
& {$[0,001]$} & {$[0,001]$} & {$[0,002]$} & {$[0,001]$} & {$[0,002]$} \\
\hline Obs. & 474 & 475 & 476 & 474 & 476 \\
$\mathrm{R}^{2}$ & 0,005 & 0,014 & 0,009 & 0,024 & 0,031 \\
\hline
\end{tabular}

$*, * *, y * * *$ coeficiente estadísticamente distinto de cero al nivel de 90,95 y $99 \%$.

Cada columna es una regresión lineal. Errores estándar robustos a heterocedasticidad entre corchetes.

¿Por qué trabaja de cuidacoches actualmente? (1) "Estaba trabajando de empleado pero me gusta trabajar por mi cuenta, libre". (2) "Estaba trabajando pero ganaba menos". (3) "Estaba desempleado y es el trabajo que pude conseguir". (4) "Estaba preso y es el trabajo que pude conseguir". (5) "Otra razón”. 
que vale 1 si el cuidacoches tiene permiso y 0 en otro caso), "Mujer", y la "Edad" del cuidacoches. El objetivo de estas regresiones es simplemente mostrar posibles asociaciones entre los motivos para ser cuidacoches y estas tres variables "explicativas". Como se observa en la Tabla 4, tener o no tener permiso parece estar correlacionado significativamente solo con uno de los motivos que declaran los cuidacoches: los antecedentes penales. Tener el permiso de cuidacoches está negativamente relacionado con haber estado preso.

\section{Motivos por los que trabajan en esa cuadra}

Como evidencia la Tabla 5, existen diferencias en los motivos por los que, quienes tienen el permiso de la IMM y quienes no lo tienen, están trabajando en una cuadra determinada. Cada columna de la Tabla 5 corresponde a una regresión lineal donde se pretende explicar los Motivos empleando las variables Permiso, Mujer y Edad. Estas regresiones pretenden simplemente explorar eventuales asociaciones entre tener Permiso y los Motivos para trabajar en una cuadra determinada. Los titulares de los permisos reportan como motivo que la "IMM les otorgó la cuadra" significativamente más que los que no tienen permiso. Para los que no tienen el carné de la IMM es más probable que estén en su lugar de trabajo porque un amigo o conocido los llevó (columna 3). No existen diferencias significativas por motivos de cercanía con el lugar de trabajo, por estar o no vacía la cuadra, ni por haber sido expulsados de otro lugar.

\section{TABLA 5}

MOTIVOS POR LOS QUE TRABAJA EN ESTA CUADRA

(Cuidadores con Permiso vs. sin Permiso)

\begin{tabular}{|l|c|c|c|c|c|c|}
\cline { 2 - 7 } \multicolumn{1}{c|}{} & $(1)$ & $(2)$ & $(3)$ & $(4)$ & $(5)$ & $(6)$ \\
\cline { 2 - 7 } \multicolumn{1}{c|}{} & Vivo & $\begin{array}{c}\text { No había } \\
\text { nadie }\end{array}$ & $\begin{array}{c}\text { Me trajo } \\
\text { alguien }\end{array}$ & $\begin{array}{c}\text { IMM } \\
\text { la otorgó }\end{array}$ & $\begin{array}{c}\text { Me echaron } \\
\text { de otra }\end{array}$ & $\begin{array}{c}\text { Otra } \\
\text { razón }\end{array}$ \\
\hline \multirow{3}{*}{ Permiso } & $-0,036$ & $-0,053$ & $-0,135^{* * *}$ & $0,202^{* * *}$ & 0,001 & $-0,010$ \\
& {$[0,038]$} & {$[0,047]$} & {$[0,046]$} & {$[0,031]$} & {$[0,013]$} & {$[0,032]$} \\
Mujer & 0,024 & $-0,085$ & $0,129^{*}$ & 0,099 & 0,001 & $-0,019$ \\
& {$[0,060]$} & {$[0,065]$} & {$[0,074]$} & {$[0,062]$} & {$[0,021]$} & {$[0,045]$} \\
& $-0,001$ & $-0,001$ & 0,000 & $0,003^{* *}$ & $0,001^{* *}$ & $-0,000$ \\
& {$[0,001]$} & {$[0,002]$} & {$[0,002]$} & {$[0,001]$} & {$[0,000]$} & {$[0,001]$} \\
\hline Obs. & 478 & 479 & 477 & 477 & 479 & 476 \\
$\mathrm{R}^{2}$ & 0,004 & 0,010 & 0,023 & 0,121 & 0,009 & 0,001 \\
\hline
\end{tabular}

*, **, y *** coeficiente estadísticamente distinto de cero al nivel de 90, 95 y 99\%.

Cada columna es una regresión lineal. Errores estándar robustos a heterocedasticidad entre corchetes. ¿Por qué vino a trabajar a esta cuadra y no a otra? (1) "Vivo cerca". (2) "No había nadie en esta cuadra". (3) "Me trajo un amigo o conocido". (4) "En la IMM me dijeron que esta cuadra estaba libre". (5) "Me echaron de otra cuadra". (6) "Otra razón (especificar)". 


\section{Estrategias para conseguir el usufructo de la cuadra y para defenderla}

En esta sección analizamos en primer lugar cómo harían para comenzar a trabajar en una calle donde ya hay un cuidacoches que no tiene el permiso de la IMM, en caso que ellos tengan un permiso o lo pudieran obtener. Es decir, qué beneficios piensan que les brindaría el carné de la IMM para comenzar a trabajar legalmente en una cuadra que está ocupada ilegalmente. Los mecanismos que utilizarían serían claramente dentro del marco institucional, y en menor grado por la fuerza. El $46 \%$ declara que con mostrar el permiso de la IMM el cuidacoches sin carné se retira; también declaran que podrían recurrir a la policía o a la IMM $(51 \%)$. Por último, el $22 \%$ declara que utilizarían la fuerza para poder comenzar a trabajar en esa cuadra. Estos mecanismos no son excluyentes.

Cuando distinguimos las respuestas de los trabajadores con y sin permiso vemos que no existen mayores diferencias (Tabla 6). Esto se puede explicar porque es una pregunta hipotética: "qué harían en caso que tuvieran el carné". No implica necesariamente estrategias que utilicen para comenzar a trabajar en una calle donde ya trabaje un cuidacoches sin carné de la IMM; ni implica tener el carné. Las personas de mayor edad y las mujeres declaran que utilizarían menos la fuerza para obtener la propiedad de la cuadra, y las personas de mayor edad recurrirían a la policía para poder ejercer su derecho.

\section{TABLA 6}

\section{MECANISMOS PARA COMENZAR A TRABAJAR EN UNA CUADRA DONDE HAY UN TRABAJADOR SIN PERMISO \\ (Cuidadores con Permiso vs. sin Permiso)}

\begin{tabular}{|l|c|c|c|c|c|c|}
\cline { 2 - 7 } \multicolumn{1}{c|}{} & $(1)$ & $(2)$ & $(3)$ & $(4)$ & $(5)$ & $(6)$ \\
\cline { 2 - 7 } \multicolumn{1}{c|}{} & $\begin{array}{c}\text { Muestra } \\
\text { permiso de } \\
\text { IMM }\end{array}$ & $\begin{array}{c}\text { Utiliza la } \\
\text { fuerza sin } \\
\text { ayuda }\end{array}$ & $\begin{array}{c}\text { Utiliza la } \\
\text { fuerza con } \\
\text { ayuda de } \\
\text { otros }\end{array}$ & $\begin{array}{c}\text { Pide ayuda } \\
\text { a IMM }\end{array}$ & $\begin{array}{c}\text { Pide ayuda } \\
\text { a Policía }\end{array}$ & Otra razón \\
\hline Permiso & 0,012 & $-0,035$ & $-0,011$ & 0,002 & 0,070 & $-0,064 * *$ \\
& {$[0,050]$} & {$[0,040]$} & {$[0,030]$} & {$[0,040]$} & {$[0,046]$} & {$[0,026]$} \\
Mujer & $-0,090$ & $-0,085^{*}$ & 0,010 & $0,131^{*}$ & 0,028 & 0,020 \\
& {$[0,074]$} & {$[0,050]$} & {$[0,074]$} & {$[0,062]$} & {$[0,021]$} & {$[0,045]$} \\
Edad & $-0,000$ & $-0,004^{* * *}$ & $-0,001$ & $0,003^{*}$ & $0,005 * * *$ & 0,001 \\
& {$[0,002]$} & {$[0,001]$} & {$[0,001]$} & {$[0,001]$} & {$[0,002]$} & {$[0,001]$} \\
\hline Obs. & 453 & 452 & 452 & 452 & 453 & 451 \\
$\mathrm{R}^{2}$ & 0,003 & 0,034 & 0,006 & 0,020 & 0,043 & 0,013 \\
\hline
\end{tabular}

$*$ **, y *** coeficiente estadísticamente distinto de cero al nivel de 90, 95 y 99\%.

Cada columna es una regresión lineal. Errores estándar robustos a heterocedasticidad entre corchetes. Si tuviera el permiso de la IMM ¿cómo haría para desplazar a quienes no tienen permiso para trabajar en su cuadra? (1) "Les muestro el permiso y se van; (2) "Los saco por la fuerza, yo solo"; (3) "Los saco por la fuerza con la ayuda de amigos"; (4) "La IMM los saca"; (5) "La policía los saca"; (6) "Otra opción (especificar)". 
Hirshleifer (1995) elabora un modelo que pretende reflejar las decisiones que se toman en anarquía, entendiendo anarquía como un sistema en el que los participantes pueden tomar y defender sus recursos sin regulación, sin implicar caos sino un orden espontáneo. Se extrae del modelo de Hirshleifer que la anarquía es frágil; se puede disolver y derivar en sistemas amorfos o jerárquicos. Bajo la anarquía, cada participante hace un balance en la explotación productiva del recurso y se pelea para conseguir o defender el recurso. Concluye Hirshleifer que la anarquía es sostenible solamente cuando hay retornos considerablemente decrecientes para el esfuerzo de pelear y los ingresos exceden un mínimo viable.

También analizamos las estrategias que utilizan los cuidacoches para defender la cuadra donde están trabajando. El mecanismo más utilizado es defenderse por ellos mismos (51\%). Lo siguen pedir ayuda a la Policía (33\%) o a la IMM (21\%). Existen diferencias marcadas en los mecanismos para defender el lugar de trabajo entre los cuidacoches con y sin permiso. Mientras que el $60 \%$ de los que no tienen permiso declaran que se defienden ellos solos, el $40 \%$ de los que tienen permiso se defiende sin ayuda. La diferencia, controlando por otras variables, es significativa al 1\% (Tabla 7). También existen diferencias en recurrir a la ayuda de la Policía o de la IMM para defender la cuadra. Es más probable que los trabajadores con permiso recurran a estos mecanismos institucionales. Únicamente el $26 \%$ de los cuidacoches sin permiso declara que recurrirían a la policía o a la IMM para defender su lugar de trabajo, mientras que el $64 \%$ de los que tienen permiso lo haría. La diferencia es numéricamente grande y estadísticamente significativa. En las columnas 3 y 4 de

\section{TABLA 7}

MECANISMO DE DEFENSA DE LA CUADRA FRENTE A INVASORES

(Cuidacoches con Permiso vs. sin Permiso)

\begin{tabular}{|c|c|c|c|c|c|c|c|}
\hline & (1) & (2) & (3) & (4) & (5) & (6) & (7) \\
\hline & $\begin{array}{c}\text { Pido ayuda } \\
\text { a otros } \\
\text { cuidacoches }\end{array}$ & $\begin{array}{l}\text { Pido ayuda } \\
\text { a amigos o } \\
\text { conocidos }\end{array}$ & $\begin{array}{c}\text { Pido ayuda } \\
\text { a la IMM }\end{array}$ & $\begin{array}{c}\text { Pido } \\
\text { ayuda a la } \\
\text { Policía }\end{array}$ & $\begin{array}{c}\text { Me } \\
\text { defiendo } \\
\text { solo }\end{array}$ & $\begin{array}{c}\text { No me } \\
\text { defiendo, } \\
\text { me voy }\end{array}$ & Otra razón \\
\hline $\begin{array}{l}\text { Permiso } \\
\text { Mujer } \\
\text { Edad }\end{array}$ & $\begin{array}{c}-0,049 \\
{[0,036]} \\
0,098 \\
{[0,061]} \\
-0,003^{*} \\
{[0,001]}\end{array}$ & $\begin{array}{c}-0,010 \\
{[0,035]} \\
0,025 \\
{[0,053]} \\
-0,002 \\
{[0,001]}\end{array}$ & $\begin{array}{c}0,171 * * * \\
{[0,040]} \\
0,045 \\
{[0,066]} \\
0,002 * \\
{[0,001]}\end{array}$ & $\begin{array}{c}0,203 * * * \\
{[0,045]} \\
0,141 * \\
{[0,073]} \\
0,004 * * * \\
{[0,002]}\end{array}$ & \begin{tabular}{|c}
$-0,176^{* * * *}$ \\
{$[0,048]$} \\
$-0,199 * * *$ \\
{$[0,067]$} \\
$-0,003 *$ \\
{$[0,002]$}
\end{tabular} & $\begin{array}{c}-0,059 * * * \\
{[0,016]} \\
0,072 * \\
{[0,042]} \\
-0,001 * * \\
{[0,001]}\end{array}$ & $\begin{array}{c}-0,009 \\
{[0,020]} \\
-0,002 \\
{[0,028]} \\
-0,000 \\
{[0,001]}\end{array}$ \\
\hline $\begin{array}{l}\text { Obs. } \\
\mathrm{R}^{2}\end{array}$ & $\begin{array}{l}465 \\
0,027\end{array}$ & $\begin{array}{l}465 \\
0,007\end{array}$ & $\begin{array}{l}464 \\
0,065\end{array}$ & $\begin{array}{l}464 \\
0,095\end{array}$ & $\begin{array}{l}464 \\
0,069\end{array}$ & $\begin{array}{l}464 \\
0,046\end{array}$ & $\begin{array}{l}464 \\
0,001\end{array}$ \\
\hline
\end{tabular}

$*, * *, y * * *$ coeficiente estadísticamente distinto de cero al nivel de 90,95 y $99 \%$.

Cada columna es una regresión lineal. Errores estándar robustos a heterocedasticidad entre corchetes. Si alguien lo quiere echar de esta cuadra ¿cómo se defiende? (1) "Pido ayuda a cuidacoches amigos";

(2) "Pido ayuda a otros amigos o conocidos"; (3) "Pido ayuda a la IMM"; (4) "Pido ayuda a la policía";

(5) "Me defiendo solo"; (6) "No me defiendo, me voy"; (7) "Otra opción (especificar)". 
la Tabla 7 vemos por separado la propensión a recurrir a la policía o a la IMM para defender el lugar de trabajo. Por último, para los trabajadores con permiso es menos probable que, frente a un invasor, se resignen a defender el lugar de trabajo y se vayan.

En el caso de las mujeres y de las personas de mayor edad, es más probable que recurran a la Policía y menos probable que se defiendan solas frente a invasiones.

Por tanto, vemos que los trabajadores con permiso recurren en mayor medida a los mecanismos institucionales que ofrece la sociedad para defender su propiedad, y los que no tienen el derecho de usufructo legal recurren a la fuerza (se defienden solos).

\section{Ingresos. ¿Ganan más con la obtención del permiso?}

Los cuidacoches de la muestra declaran tener ingresos promedios diarios de 409 pesos (de lunes a viernes). Si consideramos 25 jornales, el ingreso mensual sería de 10.250 pesos, superior al salario mínimo nacional (7.920 pesos a partir del 1 de enero de 2013). Existe mucha variabilidad entre algunos que declaran ingresos diarios de 20 pesos hasta 2.000 pesos. Esta importante divergencia en los ingresos percibidos entre los distintos cuidacoches motiva preguntas futuras acerca de si los cuidacoches se mueven con objetivos de ingresos por hora y por día, y cómo forman sus expectativas respecto de los ingresos (Crawford y Meng, 2011). Estas divergencias en los ingresos también ameritan mayor profundización, pues pueden estar relacionadas a la calidad de la cuadra que los cuidacoches tienen asignadas (por ejemplo cuadras con gran rotación de vehículos durante una misma hora) y también con la dispersión de diferentes habilidades de los cuidacoches para administrar su producción (De Paula y Scheinkman, 2011).

En la Tabla 8 mostramos que los cuidacoches que tienen permiso ganan 53 pesos más por día que los que se encuentran fuera del marco legal.

\section{TABLA 8}

INGRESOS

(Promedio diario de lunes a viernes)

\begin{tabular}{|l|c|}
\cline { 2 - 2 } \multicolumn{1}{c|}{} & $(1)$ \\
\cline { 2 - 2 } \multicolumn{1}{c|}{} & Ingresos \\
\hline \multirow{2}{*}{ Permiso } & $53,156^{* *}$ \\
\multirow{3}{*}{ Eujer } & {$[21,791]$} \\
& $-19,786$ \\
& {$[34,184]$} \\
\hline Observaciones & $-3,002^{* * *}$ \\
$\mathrm{R}^{2}$ & {$[0,849]$} \\
\hline
\end{tabular}

$*$, **, y *** coeficiente estadísticamente distinto de cero al nivel de 90,95 y $99 \%$.

Errores estándar robustos a heterocedasticidad entre corchetes. 
En los mercados informales donde personas se apropian un activo físico del que extraen una renta, se observa como un hecho estilizado la importante divergencia en los ingresos que genera la propiedad de ese activo (Acemoglu, Johnson y Robinson, 2001). No existe consenso acerca de las causas de estas divergencias de ingresos. Algunas explicaciones puntualizan que cuanto más seguro sean los derechos de propiedad debido a la institucionalidad imperante, mayor inversión habrá en capital humano y físico y usará de este capital de manera más eficiente: todo ello contribuirá a conseguir un mayor nivel de ingreso. Besley, Burchardi y Ghatak (2012) denuncian imperfecciones frecuentes en las instituciones de los países en vías de desarrollo que se manifiestan en la desprotección de los derechos de propiedad de los más pobres, y encuentran que las mejoras en la protección de los derechos de propiedad tienen efectos distintos dependiente del nivel de riqueza del individuo. El modelo teórico que desarrollan estos autores les permite observar las ganancias en términos de bienestar derivadas de la mejora de los derechos de propiedad. Acemoglu, Johnson y Robinson (2001 y 2012) señalan que las instituciones pueden jugar un rol relevante en la protección del derecho de propiedad: su investigación concluye en que las instituciones explican gran parte de las divergencias de ingresos entre las regiones que estudian. Albrecht, Navarro y Vroman (2009) aventuran otra posible explicación a esa divergencia en los ingresos. Estos autores señalan que una importante corriente de la literatura trata al sector informal como un sector en desventaja en un mercado laboral segmentado, pero esta concepción aparece desafiada por evidencia empírica encontrada, donde, por ejemplo, en el sector informal en América Latina tiene una marcada presencia de microempresas que no están sometidas a regulación. En este sentido, optan por trabajar en el mercado informal con el nivel de capital humano y productividad esperada en el sector formal.

Otra forma de pensar en las mayores ganancias que obtienen los cuidacoches que se encuentran dentro del marco legal es en términos del pensamiento de David Ricardo. Existen calles con distinta calidad o rentabilidad: número de autos que estacionan, tiempo en que están estacionados, cercanía con bancos o centros comerciales, poder adquisitivo de los conductores, etc. Estas calles (o tierras en términos ricardianos) son las primeras que se utilizan, las primeras respecto de las que se reclaman derechos de propiedad. A medida que se van incorporando nuevas calles al sistema, estas son menos rentables. Se genera una renta para los propietarios de las calles que primero se comenzaron a apropiar: los cuidacoches que obtuvieron el permiso de la IMM tienen en promedio 11,7 años en este trabajo, frente a 7,3 años de los que no tienen el permiso. Llegaron primero y tienen mayores ganancias.

\section{Usos de violencia o coerción frente a conductores}

El servicio que ofrecen los cuidacoches muchas veces no es solicitado por los conductores. Los cuidacoches solicitan un pago al terminar su servicio de cuidado del vehículo. El pago mínimo para que el cuidacoches se sienta satisfecho (para que "le haga buena cara" al cliente) es en promedio 6 pesos, con un mínimo de 0 y un máximo de 50 pesos. No existen diferencias significativas en este importe mínimo entre los que tienen permiso y los que no, ni entre varones y mujeres, ni por edad. 
Si el cliente estaciona varias veces y paga poco o nada, el $78 \%$ de los cuidacoches declara que no hace nada y siguen trabajando normalmente. El $17 \%$ reacciona retirando el saludo. Las formas más violentas de reaccionar (insultos, rayar el auto) suman $4 \%$.

Teníamos la hipótesis que si un cliente no paga, los cuidacoches sin permiso reaccionarían con más violencia o coerción que los que tienen el carné de la IMM. Los cuidacoches que tienen permiso correrían el riesgo de que los clientes protesten ante las autoridades municipales y sean sancionados con la pérdida del derecho de usufructo sobre la cuadra. Sin embargo, los datos recabados en la encuesta no muestran diferencias en la forma de reaccionar frente a un cliente que varias veces estaciona y da poco dinero o nada (Tabla 9).

La exigencia de pago a veces es solicitada de forma directa, y en otros casos el cliente paga por temor a sufrir alguna represalia. Sería interesante analizar los motivos por los que los conductores pagan a los cuidacoches, pero esto excede el objetivo de este artículo. Para esto habría que hacer una encuesta a los usuarios de los vehículos. Algunos posibles motivos son: (a) el cliente paga porque valora el servicio que recibe del cuidacoches; (b) el automovilista paga una propina porque así lo dictan las normas sociales; (c) paga para comprar un "seguro" y así evitar daños en su auto (producido por ladrones o por el propio cuidacoches); (d) pagan por caridad, como una limosna.

\section{TABLA 9}

USO DE VIOLENCIA O COERCION FRENTE A CONDUCTORES

(Cuidacoches con Permiso vs. sin Permiso)

\begin{tabular}{|c|c|c|c|c|c|c|c|c|}
\cline { 2 - 9 } \multicolumn{1}{c|}{} & $(1)$ & $(2)$ & $(3)$ & $(4)$ & $(5)$ & $(6)$ & $(7)$ & $(8)$ \\
\cline { 2 - 9 } \multicolumn{1}{c|}{} & $\begin{array}{c}\text { No hace } \\
\text { nada }\end{array}$ & $\begin{array}{c}\text { No lo } \\
\text { saluda }\end{array}$ & $\begin{array}{c}\text { Lo mira } \\
\text { serio }\end{array}$ & Insulta & $\begin{array}{c}\text { No cuida } \\
\text { el auto }\end{array}$ & $\begin{array}{c}\text { Le dice } \\
\text { que no } \\
\text { hay lugar }\end{array}$ & $\begin{array}{c}\text { La próxima } \\
\text { vez hace } \\
\text { algo al } \\
\text { auto }\end{array}$ & Otra \\
\hline Permiso & $-0,045$ & $-0,031$ & $-0,014$ & $-0,017$ & 0,006 & $-0,021$ & $-0,001$ & $0,061 * * *$ \\
Mujer & {$[0,040]$} & {$[0,036]$} & {$[0,026]$} & {$[0,016]$} & {$[0,024]$} & {$[0,015]$} & {$[0,006]$} & {$[0,017]$} \\
& $-0,007$ & 0,050 & 0,087 & 0,035 & 0,024 & 0,040 & $-0,006$ & $-0,004$ \\
Edad & {$[0,063]$} & {$[0,060]$} & {$[0,053]$} & {$[0,034]$} & {$[0,044]$} & {$[0,033]$} & {$[0,004]$} & {$[0,029]$} \\
& 0,002 & 0,002 & $-0,001^{*}$ & $-0,001^{*}$ & $-0,000$ & $-0,000$ & $-0,000$ & $-0,000$ \\
\hline Obs. & {$[0,001]$} & {$[0,001]$} & {$[0,001]$} & {$[0,000]$} & {$[0,001]$} & {$[0,001]$} & {$[0,000]$} & {$[0,001]$} \\
$\mathrm{R}^{2}$ & 477 & 476 & 474 & 473 & 474 & 473 & 473 & 473 \\
\end{tabular}

$*$, **, y *** coeficiente estadísticamente distinto de cero al nivel de 90, 95 y 99\%.

Cada columna es una regresión lineal. Errores estándar robustos a heterocedasticidad entre corchetes. ¿Qué hace con una persona que varias veces estaciona y le da poco o nada por su trabajo? (1) "Sigo trabajando normalmente". (2) "No lo saludo". (3) "Lo miro serio". (4) "Le digo algún insulto". (5) "No le cuido el auto si viene un ladrón o si se lo rayan". (6) "Le digo que no hay lugar, que está todo reservado". (7) "La próxima le hago algo al auto". (8) "Otra". 


\section{Heterogeneidad}

Anteriormente habíamos mostrado que las mujeres y las personas de mayor edad tienen una mayor probabilidad de contar con el permiso de la IMM. Los que tienen permiso de la IMM y los que no lo tienen se diferencian también en su aspecto externo. Para los trabajadores con permiso es significativamente más probable que estén prolijos y tengan su dentadura en mejor estado que los cuidacoches sin permiso (Tabla 10). No existen diferencias en cuanto a consumo de alcohol o lenguaje utilizado. El índice de Tipo de cuidacoches (construido como la suma de 4 variables dummy) es una variable que refleja el aspecto externo de los trabajadores, y tiene un peor valor para los trabajadores que no tienen permiso (columna 5). Estas relaciones, al igual que otras de las secciones anteriores, son descriptivas y no causales, ya que al tener el permiso pueden obtener mejores ingresos y de esa forma invertir en un mejor aspecto (vestimenta, etc.); o por tener mejor aspecto consiguen mayores propinas. Los cuidacoches de "tipo malo" tienen significativamente menores ingresos, menos hijos a cargo, peor nivel educativo, etc. 5

\section{TABLA 10}

TIPO DE CUIDACOCHES

(Cuidacoches con Permiso vs. sin Permiso)

\begin{tabular}{|l|l|l|l|l|l|}
\cline { 2 - 6 } \multicolumn{1}{c|}{} & \multicolumn{1}{c|}{$(1)$} & \multicolumn{1}{c|}{$(2)$} & \multicolumn{1}{c|}{$(3)$} & \multicolumn{1}{c|}{$(4)$} & \multicolumn{1}{c|}{$(5)$} \\
\cline { 2 - 6 } \multicolumn{1}{c|}{} & Desalineado & $\begin{array}{c}\text { Mala } \\
\text { dentadura }\end{array}$ & $\begin{array}{c}\text { Alcohol o } \\
\text { droga }\end{array}$ & $\begin{array}{c}\text { Lenguaje } \\
\text { pobre }\end{array}$ & $\begin{array}{c}\text { Indice de } \\
\text { tipo }\end{array}$ \\
\hline Permiso & $-0,164^{* * *}$ & $-0,164^{* * *}$ & $-0,045$ & $-0,031$ & $-0,442^{* * * *}$ \\
& {$[0,044]$} & {$[0,046]$} & {$[0,032]$} & {$[0,046]$} & {$[0,115]$} \\
Eujer & $-0,154^{* * *}$ & 0,028 & $-0,125 * * *$ & 0,005 & $-0,232$ \\
& {$[0,051]$} & {$[0,071]$} & {$[0,017]$} & {$[0,068]$} & {$[0,148]$} \\
& 0,001 & $0,005^{* * *}$ & $-0,001$ & $-0,001$ & 0,004 \\
& {$[0,001]$} & {$[0,002]$} & {$[0,001]$} & {$[0,002]$} & {$[0,004]$} \\
\hline Obs. & 460 & 457 & 459 & 459 & 449 \\
$\mathrm{R}^{2}$ & 0,047 & 0,034 & 0,028 & 0,002 & 0,037 \\
\hline
\end{tabular}

*, **, y *** coeficiente estadísticamente distinto de cero al nivel de 90,95 y $99 \%$.

Cada columna es una regresión lineal. Errores estándar robustos a heterocedasticidad entre corchetes.

(1) Desalineado es una variable dummy que toma el valor de 1 en caso que el cuidacoches esté desprolijo, tenga las manos sucias, el calzado roto, etc. (2) Mala dentadura toma el valor de 1 si el estado de los dientes del cuidacoches es pésimo a criterio del encuestador, y cero en caso contrario. (3) Alcohol o drogas toma el valor de 1 en caso que el cuidacoches esté tomando estas sustancias o se encuentre bajo sus efectos. (4) Lenguaje pobre toma el valor de 1 en caso que el cuidacoches utilice un lenguaje con pocas palabras, chabacano, lunfardo o plancha, y cero en caso contrario. (5) El índice de tipo es la suma de las 4 características anteriores.

5 Resultados disponibles dirigiéndose a los autores. 


\title{
Estabilidad y opciones laborales alternativas
}

El $67 \%$ de los entrevistados señala que les gustaría dejar de ser cuidacoches y tener otro trabajo, y no existen diferencias significativas entre quienes tienen permiso y quienes no lo tienen. Por otra parte, el 39\% de los que no tienen el carné de la IMM declaran que desearían trabajar más horas frente al $28 \%$ de los que tienen permiso (la diferencia es significativa al 1\%). El principal motivo por el que no tienen otro trabajo es que buscaron, pero no encontraron (43\% de las respuestas). Otros motivos son que querrían tener otro trabajo, pero no se han puesto a buscar (22\%); o que les falta capacitación o educación (12\%). La hipótesis de que los (bajos) sueldos en otros mercados eran un motivo importante para no salir de la calle parece no confirmarse, ya que el motivo "no encontré otro trabajo en el que ganara más dinero que acá" fue declarado por el $14 \%$ de los que quieren dejar de ser cuidacoches.

\begin{abstract}
Ahorro
Los trabajadores de este mercado tienen muy poca capacidad de ahorro. El $81 \%$ declara que a fin de mes no les sobra nada para ahorrar. En caso de ahorrar, el 14\% señala que la guardan ellos, el $4 \%$ que la prestan a parientes, amigos u otras personas y el $0,5 \%$ la depositan en un banco u otra institución. La hipótesis que los pobres "ahorran en ladrillos", construyendo de a poco su vivienda (Banerjee y Duflo, 2011), no se verifica en esta muestra de trabajadores, ya que solo el $1 \%$ declara que con lo que les sobra van construyendo su casa.
\end{abstract}

\section{A modo de resumen}

Para cerrar esta sección y tener un panorama general de las diferencias entre quienes tienen el permiso y quienes no lo tienen, la Tabla 11 nos provee del siguiente resumen: los que tienen permiso tienen significativamente mayor edad, reportan en mayor medida que el trabajo de cuidacoches es su principal fuente de ingreso, presentan una mejor tipología externa (en lo que se refiere a estado de dientes, lenguaje, vestimenta, consumo de sustancias), viven en la calle en menor medida, tienen una mayor cobertura de salud, y declaran tener más años como cuidacoches.

\section{CONCLUSION}

Los derechos de propiedad o usufructo afectan los resultados económicos. Así constata de manera consistente la literatura científica. Hemos analizado los resultados de una política de asignación masiva de derechos de propiedad (de usufructo) de activos físicos a personas que pertenecen al sector informal del mercado laboral y que muestran síntomas de vulnerabilidad social como son los cuidacoches. Sorprendentemente, a pesar del costo reducido y los considerables beneficios de adquirir ese derecho de 


\section{TABLA 11}

CUIDACOCHES CON PERMISO Y SIN PERMISO:

DIFERENCIAS EN LAS PRINCIPALES VARIABLES

\begin{tabular}{|l|c|c|c|c|c|c|}
\cline { 2 - 7 } \multicolumn{1}{c|}{} & $\begin{array}{c}\text { Con } \\
\text { permiso }\end{array}$ & $\begin{array}{c}\text { Sin } \\
\text { permiso }\end{array}$ & Diferencia & $\begin{array}{c}\text { Desv. } \\
\text { estándar }\end{array}$ & p-valor & Obs. \\
\hline Edad & 51,307 & 42,474 & $-8,833^{* * *}$ & 1,251 & 0,000 & 479 \\
Años de educación & 6,535 & 6,957 & 0,422 & 0,326 & 0,197 & 398 \\
Ingreso & 425,186 & 392,407 & $-32,779$ & 22,452 & 0,145 & 495 \\
Ingreso de cuidacoches & & & & & & \\
- Principal ingreso & 0,926 & 0,844 & $-0,082^{* *}$ & 0,032 & 0,010 & 401 \\
Indice de tipo (+) & 0,702 & 1,102 & $0,400^{* * *}$ & 0,105 & 0,000 & 484 \\
Ahorra & 0,202 & 0,177 & $-0,025$ & 0,040 & 0,535 & 386 \\
Vive calle & 0,051 & 0,172 & $0,121^{* * *}$ & 0,027 & 0,000 & 520 \\
Cobertura & 0,850 & 0,700 & $-0,149^{* * *}$ & 0,036 & 0,000 & 520 \\
Meses como cuidacoches & 131,402 & 72,502 & $-58,899^{* * *}$ & 7,521 & 0,000 & 510 \\
\hline
\end{tabular}

(+) El índice de tipo toma valores entre 0 y 4, y cuanto más cerca de 4 significa que el cuidacoches está peor en términos de vestimenta, lenguaje, estado de los dientes, y consumo de sustancias.

$* * *$ Significativo al 1 por ciento.

** Significativo al 5 por ciento.

* Significativo al 10 por ciento.

propiedad, la mitad de los potenciales beneficiarios han rechazado la suscripción a ese programa. Con el fin de entender este mercado de derechos de propiedad y la movilidad entre obtener el permiso o quedarse fuera del marco legal que la autoridad gubernamental de la ciudad exige, construimos una base de datos inédita que contiene información socioeconómica de cuidadores de vehículos con permiso y sin permiso del gobierno departamental, autoempleo que ha aparecido como un fenómeno nuevo, expandiéndose con extrema rapidez en las últimas dos décadas.

El presente trabajo es un análisis exploratorio. No contamos con elementos para diseñar una estrategia de identificación causal para estudiar los efectos de obtener el permiso legal en este peculiar mercado de los cuidadores de vehículos. Sin embargo, la novedad y amplitud de la base de datos construida nos permite hacer reflexiones relevantes para guiar futuras investigaciones. En particular, se destacan dentro de los resultados encontrados, cuatro observaciones. La primera es la heterogeneidad en las razones de entrada al mercado de cuidacoches. Solo poco más de la mitad señala que comenzó a trabajar de cuidacoches por estar desempleado (la literatura científica lo denomina acceso al sector informal como último recurso), mientras que una importante proporción de cuidacoches -cerca de 30\% - señala que entró al mercado buscando libertad y flexibilidad en el trabajo, y mayores remuneraciones (así, para ese 30\%, ya no es este sector informal un escape de último recurso sino una actividad deseable). La segunda constatación empírica es que el beneficio principal -por lejos- que perciben los que obtienen el permiso es la garantía de que el derecho de usufructo de la cuadra que se 
le asignó será protegido. Así, el beneficio principal de tener el permiso de cuidacoches otorgado por la autoridad gubernamental no se percibe que sea la cobertura de salud y vejez ni los beneficios monetarios extras, sino la defensa de la propiedad. La tercera evidencia encontrada es que a cerca del $70 \%$ de los cuidacoches -sin importar si tienen o no permiso de la autoridad gubernamental- les gustaría ahora cambiar de trabajo (esta observación se vuelve especialmente interesante a la hora de evaluar medidas para sacar a esas personas de la calle, pues hace referencia a sus aspiraciones). Una cuarta constatación es la existencia de capacidad de ahorro en tan solo uno de cada siete cuidacoches junto con su percepción de inexistencia de alternativas alcanzables que vayan más allá de simplemente acumular ellos mismos esos ahorros.

Estas constataciones empíricas encontradas gracias a la base de datos construida, junto con la revisión hecha de la literatura empírica y teórica acerca de los derechos de propiedad en un mercado laboral informal, nos ha motivado a comenzar el diseño de un experimento controlado de campo con aleatorización como estrategia de identificación causal del impacto de la política de asignación de permisos a los cuidacoches como instrumento para impulsar a esos trabajadores a aspirar y concretar una movilidad hacia arriba en el mercado laboral y en la inserción social.

La pregunta que queremos contestar con ese experimento no es trivial porque la obtención legal de los derechos de propiedad de las cuadras podría tener efectos muy distintos: por un lado, entregar el derecho de propiedad a un individuo podría significar que ese individuo se quede definitivamente en esa cuadra (con una bajísima productividad y quizá nula acumulación de capital humano, sin ascender en el mercado laboral, generando incentivos perversos a que otros miembros de la familia continúen trabajando allí para defender ese derecho de propiedad); por otro lado, entregar el derecho de propiedad a un individuo tiene como requisito obtener la cédula de identidad, el carné de salud, el certificado de no tener antecedentes delictivos, y todos estos documentos también son requisito para cualquier trabajo formal: en definitiva, obtener el derecho de propiedad en una cuadra puede significar volver a existir legalmente en la sociedad permitiendo ascender en el mercado laboral. Así esta investigación podría permitir la identificación de una relación causal entre la adecuación al marco legal, el empleo y la movilidad social. Este experimento será objeto de una próxima investigación.

\section{BIBLIOGRAFIA}

ACEMOGLU, D. y D. AUTOR (2011). "Skills, tasks, and technologies: Implications for employment and earnings", Handbook of labor economics 4, pp. 1043-1171.

ACEMOGLU, D., S. JOHNSON y J.A. ROBINSON (2001). "The Colonial Origins of Comparative Development: An Empirical Investigation", American Economic Review 91 (5), pp. 1369-1401.

ACEMOGLU, D., S. JOHNSON y J.A. ROBINSON (2012). "Institutions as a Fundamental Cause of Long Run", Handbook of Economic Growth 1A, pp. 386-472.

ALBRECHT, J., L. NAVARRO y S. VROMAN (2009). "The Effects of Labor Market Policies in an Economy with an Informal Sector", The Economic Journal 119 (539), pp. 1105-1129.

BANERJEE, V.A. y E. DUFLO (2011). Poor Economics: a radical rethinking of the way to fight global poverty. Public Affairs, New York. 
BANERJEE, V.A. y E. DUFLO (2006). "The Economic Lives of the Poor", Journal of Economic Perspectives, pp. 1-28.

BESLEY, J.T., K.B. BURCHARDI y M. GHATAK (2012). "Incentives and the De Soto Effect", Quarterly Journal of Economics 127 (1), pp. 237-282.

BESLEY, J.T., K.B. BURCHARDI y M. GHATAK (2010). "Property Rights and Economic Development", Handbook of Development Economics 5, pp. 4525-4595.

BESLEY, J.T. (1995). "Property Rights and Investment Incentives: Theory and Evidence from Ghana", Journal of Political Economy 103 (5), pp. 903-937.

BUCHELI, M. y R. CENI (2007). "Informality: Sectoral Selection and Earnings in Uruguay". Documento de Trabajo 20/07. Departamento de Economía, Facultad de Ciencias Sociales, UdelaR.

CRAWFORD, V.P. y J. MENG (2011). "New York City Cab Drivers' Labor Supply Revisited: ReferenceDependent Preferences with Rational-Expectations Targets for Hours and Income", American Economic Review 101, pp. 1912-1932.

DE PAULA, A. y J.A. SCHEINKMAN (2011). "The Informal Sector: An Equilibrium Model and Some Empirical Evidence from Brazil", The Review of Incomes and Wealth 57 (1), pp. 1-22.

DEMSETZ, H. (1967). “Towards a Theory of Property Rights”, American Economic Review P\&P 57 (2), pp. 347-359.

FIELD, E. (2007). "Entitled to Work: Urban Property Rights and Labor Supply in Peru", Quarterly Journal of Economics 122 (4), pp. 1561-1602.

FIELDS, S.G. (2004). "A Guide to Multisector Labor Market Models", Cornell University, School of Industrial and Labor Working Papers, pp. 1-50.

FUGAZZA, M. y J. JACQUES (2003). "Labor Market Institutions, Taxation and the Underground Economy", Journal of Public Economics 88, pp. 395-418.

GALIANI, S. y E. SCHARGRODSKY (2010). "Property Rights for the Poor: Effects of land titling", Journal of Public Economics 94, pp. 700-729.

GANDELMAN, N. (2009). "Inter-Generational Effects of Titling Programs: Physical vs. Human Capital" Documento de investigación $\mathrm{N}^{\circ} 50$, Universidad ORT.

GËRXHANI, K. (2004). "The Informal Sector in Developed and Less Developed Countries", Public Choice, pp. 1-29.

HIRSHLEIFER, J. (1995). “Anarchy and Its Breakdown”, Journal of Politic Economy 103 (1), pp. 26-52.

LANJOUW, O.J. y P.I. LEVY (2002). "Untitled: A Study of Formal and Informal Property Rights in Urban Ecuador", Economic Journal 112 (482), pp. 986-1019. 


\title{
8. ANEXOS
}

\author{
ANEXO 1 \\ DEFINICION Y DESCRIPCION DE LAS VARIABLES \\ MONTEVIDEO, 2013
}

\begin{tabular}{|c|c|c|c|c|c|}
\hline Variable & Media & $\begin{array}{c}\text { Desv. } \\
\text { estándar }\end{array}$ & Mín & Máx. & Obs. \\
\hline $\begin{array}{l}\text { Permiso } \\
\text { Mujer } \\
\text { Edad } \\
\text { Educ. máx: Primaria }\end{array}$ & $\begin{array}{r}0,50 \\
0,11 \\
46,77 \\
0,60\end{array}$ & $\begin{array}{r}0,50 \\
0,31 \\
14,31 \\
0,49\end{array}$ & $\begin{array}{r}0 \\
0 \\
18 \\
0\end{array}$ & $\begin{array}{r}1 \\
1 \\
85 \\
1\end{array}$ & $\begin{array}{l}507 \\
519 \\
496 \\
507\end{array}$ \\
\hline $\begin{array}{l}\text { ¿Por qué trabaja de cuidacoches? - } \\
\text { Quiere trabajar por su cuenta } \\
\text { ¿Por qué trabaja de cuidacoches? - } \\
\text { Ganaba menos en otro trabajo } \\
\text { ¿Por qué trabaja de cuidacoches? } \\
\text { - Desempleado } \\
\text { ¿Por qué trabaja de cuidacoches? - Preso } \\
\text { ¿Por qué trabaja de cuidacoches? - Otra } \\
\text { razón (especificar) } \\
\text { ¿Por qué trabaja de cuidacoches? - } \\
\quad \text { Razón principal (1 al 6) }\end{array}$ & $\begin{array}{l}0,25 \\
3,17\end{array}$ & $\begin{array}{l}0,37 \\
0,33 \\
0,49 \\
0,19 \\
0,44 \\
1,26\end{array}$ & $\begin{array}{l}0 \\
0\end{array}$ & $\begin{array}{l}1 \\
1\end{array}$ & $\begin{array}{l}509 \\
493\end{array}$ \\
\hline $\begin{array}{l}\text { ¿Por qué vino a trabajar a esta cuadra y } \\
\text { no a otra? - Vive cerca } \\
\text { ¿Por qué vino a trabajar a esta cuadra y } \\
\text { no a otra? - Cuadra libre } \\
\text { ¿Por qué vino a trabajar a esta cuadra y } \\
\text { no a otra? - Por amigo } \\
\text { ¿Por qué vino a trabajar a esta cuadra y } \\
\text { no a otra? - IMM indicó cuadra libre } \\
\text { ¿Por qué vino a trabajar a esta cuadra y } \\
\text { no a otra? - Lo echaron de otra } \\
\text { Hay que pedir permiso a referente de la } \\
\text { zona }\end{array}$ & 0,19 & $\begin{array}{l}0,39 \\
0,47\end{array}$ & 0 & 1 & $\begin{array}{l}514 \\
515 \\
513 \\
513 \\
515 \\
504\end{array}$ \\
\hline $\begin{array}{l}\text { Para desplazar a los que no tiene permiso } \\
\text { de IMM - Mostrar permiso propio } \\
\text { Para desplazar a los que no tiene permiso } \\
\text { de IMM - Por la fuerza propia } \\
\text { Para desplazar a los que no tiene permiso } \\
\text { de IMM - Con la ayuda de amigos } \\
\text { Para desplazar a los que no tiene permiso } \\
\text { de IMM - IMM los saca } \\
\text { Para desplazar a los que no tiene permiso } \\
\text { de IMM - Policía los saca }\end{array}$ & 0,21 & 0,41 & 0 & 1 & 484 \\
\hline $\begin{array}{l}\text { Defensa de la cuadra: Pide ayuda a } \\
\text { cuidacoches } \\
\text { Defensa de la cuadra: Pide ayuda a } \\
\text { amigos }\end{array}$ & 0,16 & 0,37 & 0 & 1 & 498 \\
\hline
\end{tabular}




\begin{tabular}{|c|c|c|c|c|c|}
\hline Variable & Media & $\begin{array}{l}\text { Desv. } \\
\text { estándar }\end{array}$ & Mín & Máx. & Obs. \\
\hline Defensa de la cuadra: pide ayuda IMM & 0,21 & 0,41 & 0 & 1 & 497 \\
\hline Defensa de la cuadra: pide ayuda policía & 0,33 & 0,47 & 0 & 1 & 497 \\
\hline Defensa de la cuadra: se defiende solo & 0,51 & 0,50 & 0 & 1 & 497 \\
\hline Defensa de la cuadra: se va & 0,05 & 0,21 & 0 & 1 & 497 \\
\hline $\begin{array}{l}\text { Si se le ofreciera volver a estudiar ahora, } \\
\text { ¿volvería a estudiar? }\end{array}$ & 0,49 & 0,50 & 0 & 1 & 510 \\
\hline ¿Tiene hijos a su cargo menores de 18 & & & & & \\
\hline pensión) & 0,31 & 0,46 & 0 & 1 & 512 \\
\hline ¿Cuántos? & 2,03 & 1,23 & 1 & 6 & 156 \\
\hline $\begin{array}{l}\text { ¿Ese permiso de la IMM es suyo } \\
\text { personal o es de otra persona? }\end{array}$ & 0,96 & 0,21 & 0 & 1 & 248 \\
\hline $\begin{array}{l}\text { Beneficios del permiso de la IMM: La } \\
\text { cuadra es mía }\end{array}$ & 0,70 & 0,46 & 0 & 1 & 239 \\
\hline $\begin{array}{l}\text { Beneficios del permiso de la IMM: } \\
\text { Mejores propinas }\end{array}$ & 0,14 & 0,34 & 0 & 1 & 237 \\
\hline Beneficios del permiso de la IMM: & & & & & \\
\hline Aporto BPS & 0,04 & 0,20 & 0 & 1 & 236 \\
\hline & 0,14 & 0,34 & 0 & 1 & 234 \\
\hline Beneficios del permiso de la IMM: & & & & & \\
\hline Defensa de la cuadra por la policía & 0,19 & 0,39 & 0 & 1 & 237 \\
\hline \multirow{6}{*}{$\begin{array}{l}\text { No obtuvo permiso IMM por: No diner } \\
\text { trámites } \\
\text { No obtuvo permiso IMM por: No info } \\
\text { No obtuvo permiso IMM por: Difícil } \\
\quad \text { tramit. Carné de Salud } \\
\text { No obtuvo permiso IMM por: Mal } \\
\quad \text { análisis Carné de Salud } \\
\text { No obtuvo permiso IMM por: No sacó } \\
\text { certificado buena conducta }\end{array}$} & 0,19 & 0,39 & 0 & 1 & 255 \\
\hline & 0,19 & 0,40 & 0 & 1 & 254 \\
\hline & 0,08 & 0,27 & 0 & 1 & 254 \\
\hline & & & & & \\
\hline & 0,04 & 0,19 & 0 & 1 & 254 \\
\hline & 0,09 & 0,29 & 0 & 1 & 255 \\
\hline \multirow{2}{*}{$\begin{array}{l}\text { No obtuvo permiso IMM por: Queda } \\
\text { lejos IMM }\end{array}$} & & & & & \\
\hline & 0,11 & 0,32 & 0 & 1 & 254 \\
\hline $\begin{array}{l}\text { No obtuvo permiso IMM por: Pierdo } \\
\text { horas de trabajo }\end{array}$ & 0,21 & 0,41 & 0 & 1 & 255 \\
\hline \multirow{3}{*}{$\begin{array}{l}\text { No obtuvo permiso IMM por: Sin cédula } \\
\text { No obtuvo permiso IMM por: Fotos } \\
\text { carné }\end{array}$} & 0,06 & 0,24 & 0 & 1 & 255 \\
\hline & & & & & \\
\hline & 0,02 & 0,14 & 0 & 1 & 254 \\
\hline \multirow{5}{*}{$\begin{array}{l}\text { No obtuvo permiso IMM por: } \\
\text { Complicado sacar el permiso } \\
\text { No obtuvo permiso IMM por: No } \\
\text { necesito permiso } \\
\text { No obtuvo permiso IMM por: No gano } \\
\text { nada con el permiso } \\
\text { No obtuvo permiso IMM por: No tengo } \\
\text { ganas }\end{array}$} & & & & 1 & \\
\hline & 0,13 & 0,34 & 0 & 1 & 255 \\
\hline & 0,25 & 0,44 & 0 & 1 & 257 \\
\hline & 0,13 & 0,34 & 0 & 1 & 254 \\
\hline & 019 & 039 & 0 & 1 & 256 \\
\hline ¿Cuánt & & & & & \\
\hline Por día entre semana? & 408,74 & 249,94 & 20 & 2.000 & 495 \\
\hline
\end{tabular}




\begin{tabular}{|c|c|c|c|c|c|}
\hline Variable & Media & $\begin{array}{l}\text { Desv. } \\
\text { estándar }\end{array}$ & Mín & Máx. & Obs. \\
\hline $\begin{array}{l}\text { ¿Tiene que darle a alguien parte de lo } \\
\text { que gana para que lo deje trabajar en } \\
\text { la cuadra? } \\
\text { ¿Cuánto se le paga por semana? }\end{array}$ & $\begin{array}{r}0,04 \\
502,22\end{array}$ & $\begin{array}{r}0,20 \\
869,29\end{array}$ & $\begin{array}{r}0 \\
20\end{array}$ & $\begin{array}{r}1 \\
2.800\end{array}$ & $\begin{array}{r}477 \\
9\end{array}$ \\
\hline $\begin{array}{l}\text { Dinero mínimo para ser amable } \\
\text { Si dan poco dinero: Trabaja normalmente } \\
\text { Si dan poco dinero: No saluda } \\
\text { Si dan poco dinero: Mira serio } \\
\text { Si dan poco dinero: Insulta } \\
\text { Si dan poco dinero: No cuida auto } \\
\text { Si dan poco dinero: Dice no hay lugar } \\
\text { Si dan poco dinero: Raya auto }\end{array}$ & $\begin{array}{l}6,10 \\
0,80 \\
0,20 \\
0,09 \\
0,04 \\
0,09 \\
0,03 \\
0,00\end{array}$ & $\begin{array}{l}8,09 \\
0,40 \\
0,40 \\
0,29 \\
0,19 \\
0,28 \\
0,16 \\
0,07\end{array}$ & $\begin{array}{l}0 \\
0 \\
0 \\
0 \\
0 \\
0 \\
0 \\
0\end{array}$ & $\begin{array}{r}50 \\
1 \\
1 \\
1 \\
1 \\
1 \\
1 \\
1\end{array}$ & $\begin{array}{l}379 \\
496 \\
446 \\
442 \\
440 \\
443 \\
439 \\
439\end{array}$ \\
\hline $\begin{array}{l}\text { ¿Le gustaría dejar de ser cuidacoches? } \\
\text { ¿Por qué no tiene otro trabajo?: No buscó } \\
\text { ¿Por qué no tiene otro trabajo?: No } \\
\quad \text { encontró } \\
\text { ¿Por qué no tiene otro trabajo?: Sin } \\
\quad \text { educación } \\
\text { ¿Por qué no tiene otro trabajo?: Gana } \\
\text { más acá } \\
\text { ¿Por qué no tiene otro trabajo?: Quiere } \\
\quad \text { horario libre } \\
\text { ¿Por qué no tiene otro trabajo?: Trabajos } \\
\quad \text { inestables }\end{array}$ & $\begin{array}{l}0,67 \\
0,25 \\
0,48\end{array}$ & $\begin{array}{l}0,47 \\
0,43 \\
0,50\end{array}$ & $\begin{array}{l}0 \\
0\end{array}$ & $\begin{array}{l}1 \\
1\end{array}$ & $\begin{array}{l}511 \\
301\end{array}$ \\
\hline $\begin{array}{l}\text { ¿Busca otro trabajo? } \\
\text { ¿Es para sustituir el trabajo actual o para } \\
\quad \text { complementarlo? }\end{array}$ & $\begin{array}{l}0,33 \\
0,61\end{array}$ & $\begin{array}{l}0,47 \\
0,49\end{array}$ & 0 & 1 & 507 \\
\hline $\begin{array}{l}\text { Ahorra } \\
\text { Ahorra y guarda él } \\
\text { Ahorra y guarda pariente/amigo } \\
\text { Ahorra en banco } \\
\text { Ahorra y presta } \\
\text { Ahorra y construye } \\
\text { Ahorra y compra para vender } \\
\text { No ahorra }\end{array}$ & $\begin{array}{l}0,19 \\
0,14 \\
0,02 \\
0,00 \\
0,01 \\
0,01 \\
0,01 \\
0,81\end{array}$ & $\begin{array}{l}0,39 \\
0,35 \\
0,15 \\
0,05 \\
0,12 \\
0,07 \\
0,07 \\
0,39\end{array}$ & $\begin{array}{l}0 \\
0 \\
0 \\
0 \\
0 \\
0 \\
0 \\
0\end{array}$ & $\begin{array}{l}1 \\
1 \\
1 \\
1 \\
1 \\
1 \\
1 \\
1\end{array}$ & $\begin{array}{l}387 \\
385 \\
375 \\
375 \\
374 \\
374 \\
374 \\
387\end{array}$ \\
\hline $\begin{array}{l}\text { Desalineado } \\
\text { Dentadura mal } \\
\text { Alcohol/Droga } \\
\text { Lenguaje pobre } \\
\text { Indice de tipo }\end{array}$ & $\begin{array}{l}0,28 \\
0,66 \\
0,12 \\
0,30 \\
1,36\end{array}$ & $\begin{array}{l}0,45 \\
0,47 \\
0,33 \\
0,46 \\
1,20\end{array}$ & $\begin{array}{l}0 \\
0 \\
0 \\
0 \\
0\end{array}$ & $\begin{array}{l}1 \\
1 \\
1 \\
1 \\
4\end{array}$ & $\begin{array}{l}495 \\
492 \\
493 \\
494 \\
483\end{array}$ \\
\hline $\begin{array}{l}\text { Años de cuidacoches } \\
\text { Años de cuidacoches en esa cuadra }\end{array}$ & $\begin{array}{l}9,69 \\
7,95\end{array}$ & $\begin{array}{l}7,27 \\
6,52\end{array}$ & $\begin{array}{l}1 \\
1\end{array}$ & $\begin{array}{l}40 \\
38\end{array}$ & $\begin{array}{l}442 \\
403\end{array}$ \\
\hline
\end{tabular}




\section{ANEXO 2A}

UBICACION DE LOS CUIDACOCHES ENTREVISTADOS

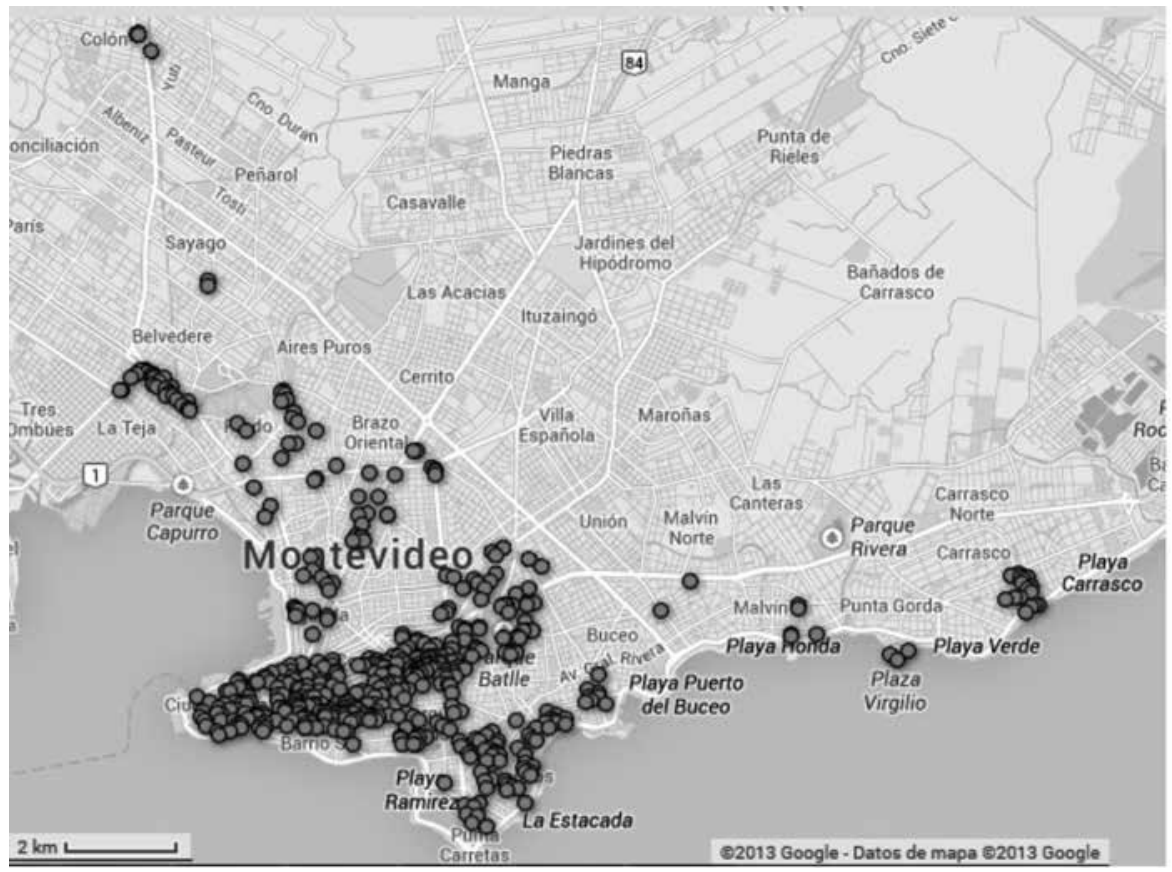

ANEXO 2B

UBICACION DE LOS CUIDACOCHES ENTREVISTADOS (VISTA AMPLIADA)

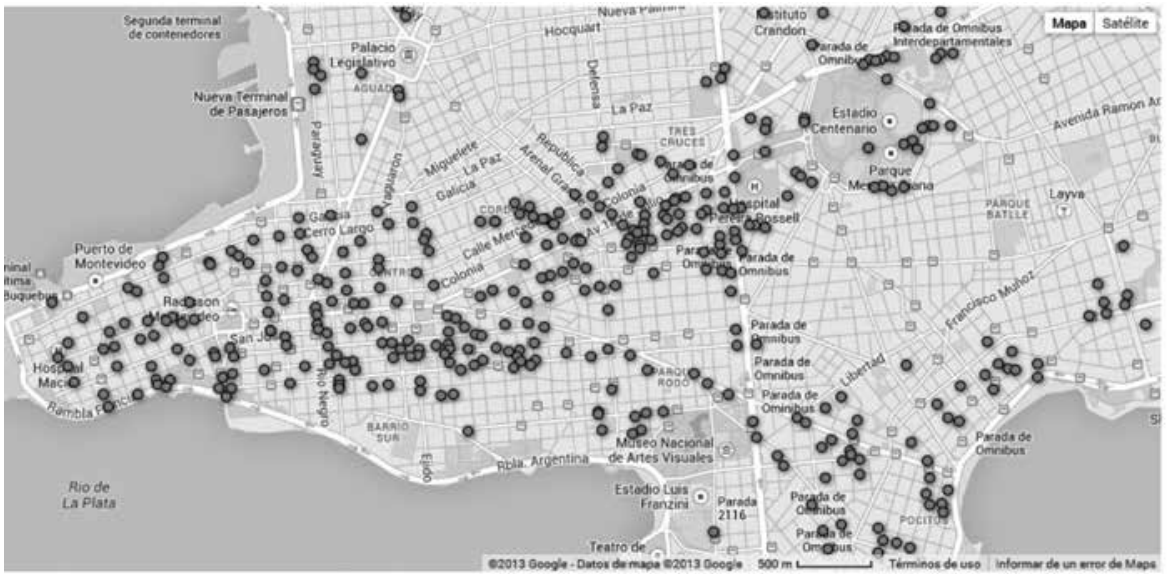

